\title{
Construction of Law-based Government in the Context of Counteraction to COVID-19
}

\author{
Wendao Tang \\ Student, Guangdong University of Petrochemical Technology (Maoming, China) \\ E-mail: 2059180201@qq.com \\ https://orcid.org/0000-0003-1234-5332

\section{Xuelu Qiu} \\ Ph.D. Candidate, Lecturer, Guangdong University of Petrochemical Technology \\ (Maoming, China) \\ E-mail: 369529836@qq.com \\ https://orcid.org/0000-0002-0411-3120
}

Tang, Wendao, and Xuelu Qiu (2020) Construction of Law-based Government in the Context of Counteraction to COVID-19. Ukrainian Policymaker, Volume 6, 74-84. https://doi. org/10.29202/up/6/8

With the deepened construction of law-based government in China, China-specific socialist legal systems have been constantly improved. Among these systems, the legal system on public health security is an important part of the construction. In the context of preventing and controlling COVID-19, Chinese emergency response measures for public health security have played crucial roles. They created the most important legal framework for China to effectively prevent and control COVID-19, protect the life and health of its citizens, and guarantee the resumption of work and production. Nevertheless, the fight against coronavirus disease has caused many problems, including the need to legally give the government more specific powers in the event of serious public health emergencies, how to get the government to get legal powers and to carry out preventive work promptly, how the Government should better protect fundamental rights citizens in critical situations to prevent and control epidemics, and how to ensure that the local government operates in accordance with the law in preventing and controlling COVID-19. This article analyzes the legal standardization of legal issues that arise in the context of the prevention and control of COVID-19 by the Chinese government in terms of building a legal government Discuss ways to improve the construction of a legal government in the country context of counteraction COVID-19.

Keywords: law-based government, counteraction to COVID-19, public health security, government power

Received: February 21, 2020; accepted: March 24, 2020

(C) Tang, Wendao, 2020

(C) Qiu, Xuelu, 2020 


\section{Summary of COVID-19 Prevention, Control, and Law-based Government}

\section{Concept of Law-based Government}

Law-based government is opposed to the "man-ruled" in specific contexts of China. Over thousands of years of Chinese history, the emperors ruled their states with their scholar-bureaucrats. However, former empires and dynasties formulated their respective laws according to the needs of social governance in their times. Hence, a unique tradition developed for ruling by men in spite of the law. At present, the Chinese government adopts the centralized government system, so it is quite necessary to regulate government power with law and construct the law-based government.

Also, law-based government is seldom mentioned in Western countries, because in modern Western countries, the government mostly originates from legal authorization, and law come into being prior to the government. Therefore, people living under Western cultural backgrounds generally consider that the governments are naturally constructed in accordance with the law and restricted by law. The governments must exercise their power pursuant to law, in order to protect, safeguard and expand citizens' rights.

Concerning the law-based government, Aristotle, who is a western ancient Greek scholar, thinks that the law-based government means existing law is sound that people can generally abide by and enforce the law (Aristotle, 2013). As an ancient Greek scholar, Cicero opposes ruling by men and considers that no one shall enjoy this privilege under the ruling of the law-based government (Zhang, 2008). British scholar Locke considers that a law-based government ought to establish restricted, responsible and decentralized principles. All powers shall be exercised in accordance with announced law. Besides, everyone is equal in front of law, and violators of law must be punished by law. French scholar Montesquieu thinks that an ideal law-based government shall separate executive, legislative and judicial powers. At the same time, Rousseau considers that a law-based government shall be constructed based on social contracts (Rousseau, 2004). Even though there are divergent opinions regarding the law-based government in the academic circle and the definition of law-based government hasn't been unified, it is beyond doubt that the law-based government has emerged as specified by constitutions and law. The government's exercising of public power must be restricted and supervised by law (Bazaluk \& Balinchenko, 2020). Citizens' rights are protected and relieved by law. Meanwhile, law shall be continuously improved in combination with productivity and the situation of social development."

\section{Relationship between Epidemic and the Construction of Law-based Government}

Epidemic prevention and control are closely connected with the construction of law-based government. During epidemic prevention and control, the construction of law-based government is an important part. Counteraction to epidemic, in essence, refers to the government's emergent ruling by law. For such prevention and control, constitutions and pertinent law authorize the government to take exceptional law to stabilize social order under special circumstances, standardize and restrict some of the citizens' rights and behaviors to protect more important rights of citizens like their lives, in order that the country and the society can gradually return to the normal track of ruling by law. In the course of epidemic prevention and control, namely emergent ruling by law, particularly evident features include centralization and expansion of national power as well as restriction and abatement of civil rights. 
For the construction of law-based government, what matters most is that the government's exercising of power must be authorized, standardized, restricted and supervised by law. Meanwhile, relief and guarantees shall be offered for civil rights. However, it will be extremely hard for the government to effectively deal with emergencies to effectively control the epidemic, provided that no effort is made to centralize or expand the government's power and restrict citizens' rights. As a consequence, social disorders, social chaos, greater losses of civil rights, and more legal issues. Therefore, the key point consists in the scope and degree to which the government's power is centralized and expanded within the law, and to which citizens' rights are restricted and weakened during epidemic prevention and control. The purpose is to make the government's exercising of power for epidemic prevention cause minimal damages to citizens, thus best preventing and controlling the epidemic. Some cases in the context of counteraction to COVID-19 suggest that the government's exercising of their expanded power, especially the local government's acts might beyond the legal requirements for COVID-19 prevention and control in some fields have brought some unnecessary obstacles to the construction of law-based government and caused some legal issues. It is quite necessary to further improve the legal systems for the above construction in consideration of the legal issues (Huang, 2015).

\section{Legal Issues Emerging in Constructing the Law-based Government in Epidemic Prevention and Control}

\section{Lack of Emergency Law}

Since the outbreak of COVID-19 in the world, several Western countries, led by the United States, has declared their state of emergency. The emergency state system is a prevalent practice in most modern countries. The Emergency Act was promulgated in 1955 in France; the National Emergencies Act was promulgated in 1976 in the United States; the Federal Emergency Act was promulgated in 2001 in Russia. In promulgating unified emergency acts, the Western countries formulated special laws specific to particular emergencies based on scientific classification. Special laws and regulations have been formulated in response to public health events, natural disasters, emergencies, states of emergencies and terrorist attacks, and so on. Besides, they are often revised according to the actual situation.

In China, legal authorities that state organs at varying levels enjoy in case of any emergencies are specified in the Chinese Constitution. Still, epidemic prevention and control from the perspective of systems and architectures are not defined by law. Besides, the law regarding emergency responses to unexpected epidemics and diseases approved by the Standing Committee of the National People's Congress are relatively scattered. Although the Emergency Headquarters for joint prevention and control (hereinafter referred to as HQs) have been granted certain legal rights, including the rights to isolate infected cases and lockdown affected areas in the process of COVID-19 prevention and control by the Emergency Response Law of the People's Republic of China, Regulations on Public Health Emergency and Law of the People's Republic of China on the Prevention and Treatment of Infectious Diseases, Concerning if the HQs can authorize local governments and local autonomous organizations the rights to restrict citizens' personal freedom with compulsive measures, the Organic Law of the Villagers Committees of the People's Republic of China and the Organic Law of the Urban Residents Committees of the People's Republic of China stipulates that local autonomous organizations don't have such legal rights. According to Article 8 of the Legislation Law, only the National People's Congress and the Standing Committee have the right to formulate 
laws to specify mandatory measures for restricting personal freedom. The State Council and corresponding HQs for joint epidemic prevention and control are not authorized to restrict citizens' personal freedom with compulsory measures.

According to Clause 3, Article 10 of the Administrative Compulsory Law of the People's Republic of China, “Administrative compulsory measures mustn't be specified in regulatory documents other than law and regulations." Some administration regulations, including Article 33 of the Detailed Implementation Rules on Health Management in Public Areas and administrative measures taken by some local governments for epidemic prevention and control such as compulsory isolation and restriction of personal freedom, are not definitely permitted by law. However, in reality, it is essential to expand these organizations' power to prevent and control the epidemic effectively. Since the stage of emergency is specified in the Constitution, under a state of emergency, the law still has to clarify the legal rights of related anti-epidemic organizations.

Also, the subjects, components, statutory procedures, legal responsibilities, and legal authorities of the HQs for joint prevention and control at varying levels aren't clearly defined in any law either. In legal systems, the Emergency Response Law of the People's Republic of China is a mere legal regulation on emergency response plans to various emergencies. It does not grant temporary rights to some organizations and local governments which do not have related rights in any major public health emergencies to protect most citizens'rights under the state of an emergency or clarifies the definite boundaries for expanding government power under the stage of an emergency. Thus, existing legal systems on public emergency responses can't constitute a complete legal system on emergency responses, in order to take administrative measures beyond legal authorities for better epidemic prevention and control. Likewise, in view that laws are formulated for the purpose of protecting citizens' rights, China shall also endow the governments with more power than they usually have to prevent and control the epidemic.

Nevertheless, from the legislation system of China, no emergency law has been formulated in China to grant governments more power than they normally have for epidemic prevention and control under the state of an emergency through legal procedures. The governments' power for taking measures against the epidemic is mostly granted by law and regulations, including the Emergency Response Law of the People's Republic of China, Martial Law of the People's Republic of China, State Security Law of the People's Republic of China, Law of the People's Republic of China on the Prevention and Treatment of Infectious Diseases, Frontier Health and Quarantine Law of the People's Republic of China, Animal Epidemic Prevention Law of the People's Republic of China, Food Safety Law of the People's Republic of China, Law of the People's Republic of China on Penalties for Administration of Public Security and Criminal Law of the People's Republic of China. So many laws specify the expansion of government power for epidemic prevention and control under special circumstances that legal systems are disorderly. Despite many related laws and regulations in legal systems, structurally, no complete system has come into being.

\section{Some Local Governments' Deviation from the Principle of Proportionality in Law Enforcement}

The principle of proportionality in administrative law should be respected in order to minimize the damage caused by government powers to prevent and control epidemics. This implies that administrative subjects shall consider the realization of administrative objectives and protection of administrative counterparts' rights and interests in conducting administrative 
behaviors. If the realization of administrative goals might impose adverse impacts upon administrative counterparts' rights and interests, such adverse impacts shall be minimized and limited at an appropriate proportion.

The principle of proportionality is not clearly provided in Chinese law. The State Council specifies the principles of rationality and proportionality in the Opinions on Strengthening the Building of a Government Ruled by Law (Document No.33 [2010] of the State Council) (Research Center, 2014). Whether administrative behaviors are in line with the principle of proportionality is an important legal criterion for reviewing administrative justices. In particular, under the circumstances of an emergency ruling by law like epidemic prevention and control, restrictions on citizens' freedom and rights such as city lockdown, neighborhood lockdown, expropriation, requisition, and traffic regulation shall conform to the principle of proportionality. Take the "expropriation event in Dali" in the context of counteraction to COVID-19, for example. Dali Health Bureau expropriated approximately 300,000 masks bought by Chongqing and Huangshi municipal governments from Myanmar with the excuse of responding to the emergency (COVID-19). This event aroused great controversies about administrative law. Administrative power shall be exercised in accordance with "the principle of proportionality." There shall be an appropriate, requisite, balanced, and definite proportion between the goals of administrative measures and means for attaining such goals. It is evident that Dali Health Bureau ignored the proportion between the administrative measures for expropriating masks and the nationwide COVID-19 prevention. Its practice is unfavorable for coordinating COVID-19 prevention and control all over China. Meanwhile, it is not in line with the principle of proportionality in administrative law.

Articles 6 and 9 of the People's Republic of China Law on the Prevention and Treatment of Infectious Diseases, as well as Articles 4 and 6 of the Public Health Emergency Regulation, provide governments with legal authority to take specific measures to prevent and combat epidemics. However, they do not have a clear indication of government bodies, relevant legal duties or legal procedures. Instead, they only generally provide that emergency HQs shall deal with emergencies and isolate sources of infection. Such soft clauses of law, on the one hand, are favorable for the governments to take flexible measures under the epidemic situation; on the other hand, they obscure the boundaries of government power. As a result, power is inappropriately employed, and some behaviors even go beyond the reasonable limits of prevention and control. There are lots of cases on similar administrative acts conducted beyond the reasonable limits in the context of counteraction to COVID-19. For instance, some local governments locked down places like food markets for epidemic prevention and control, imposing adverse impacts on people's daily lives. In some affected areas, hospitals ignored females' basic physiological needs, excluded sanitary pads from disaster relief materials. Apparently, these practices went beyond the principle of proportionality in administrative law and the reasonable limits necessary for epidemic prevention and control, thereby having negative impacts on administrative counterparts.

\section{Some Local Governments' Outdated Ideas on Ruling by Law}

Although both central and local governments established joint prevention and control mechanisms for COVID-19 prevention and control, the execution and implementation of these mechanisms shall be still dependent upon local governments and organizations. However, in preventing and controlling COVID-19, some local governments and organizations took measures beyond legal authorities. 
During their prevention of COVID-19, some rural local organizations adopted "hardcore" actions, some of which were unlawful and unreasonable. For example, in some countryside of affected areas, villagers' committees committed some rude acts, including road and village lockdown. Entries and roads to villages were blocked with stones, stumps, cement blocks, welded iron fences, and sandy soil by excavators. Nevertheless, according to Article 43 of the Law of the People's Republic of China on the Prevention and Treatment of Infectious Diseases, "In case of the outbreak or epidemic of class-A and class-B infectious diseases, regional people's governments above the prefecture-level can declare administrative areas under their jurisdiction as affected areas in part or whole once they report to the higher-level people's governments for approval. The State Council can confirm and declare affected areas across provinces, autonomous areas, and municipalities directly under the central government". Local people's governments above the prefecture-level can adopt emergency measures stipulated in Article 42 of this law, and perform health quarantine inspection on personnel, materials, and means of transport going into and out of affected areas. People's governments of provinces, autonomous areas and municipalities directly under the central government can decide to lock down places of their administrative areas affected by class-A infectious disease.

Nevertheless, decisions regarding whether to block big or medium-sized affected areas, affected areas across provinces, autonomous areas or municipalities directly under the central government, or lockdown affected areas which will cause interruption of traffic arteries or the State Council shall make borders. The lockdown lifting of affected areas shall be determined and announced by the original authorities, which have made corresponding decisions." Any law or regulations do not permit the measures taken by villagers' committees. Being unlawful, they violate the Fire Protection Law of the People's Republic of China, Road Traffic Safety Law of the People's Republic of China, and Criminal Law of the People's Republic of China. This fully reveals local governments' and local organizations' lack of ideas on governance and ruling by law. Besides, some prefecture-level municipal governments' administrative behaviors were unlawful and unreasonable during epidemic prevention. For example, some local residents' committee released notices and required residents to dispose of their pets independently, or else the pets would be compulsorily killed. Neither local governments issued any order for killing pets, nor any evidences proved that pets were "affected" species. However, local staff killed residents' pets. Besides, local governments arbitrarily set up checkpoints at entrances of neighborhoods, townships, towns, and villages to check citizens' certificates like ID cards. Nonetheless, according to Article 13 of the Law of the People's Republic of China on Resident Identity Cards, people's police shall be the subjects checking resident identity cards. However, property management personnel of neighborhoods and local ordinary people do not have the power.

In preventing and controlling COVID-19, some local governments' ruling in chaos reflected the harms of local governments' old-fashioned ideas on ruling by law to the construction of law-based government.

\section{Suggestions for Improving the Construction of Law-based Government during Epidemic Prevention and Control}

\section{Improving Legal Systems for Public Health Emergency Responses}

As mentioned above, China still faces many legal issues in establishing legal systems for responding to major public health emergencies, and the most outstanding legal issue is China's 
lack of an emergency law. There are legal provisions regarding the state of emergency in the Constitution of the People's Republic of China. In fact, many legal issues emerged under the SARS epidemic situation in 2002 when legislation authorities realized that there was a lack of legal supports for responding to similar emergencies, plenty of measures were connected with legal issues, curfew measures were inadequate, and China should formulate an emergency law. Hence, the "curfew" under three non-recurrent legal states in Article 26 of the amendment to the 2004 constitution was replaced by the "state of emergency," and the emergency law was drafted, and phrases of relevant legal provisions were revised. However, the draft was not approved, so there is no special emergency law in response to emergencies in China.

The nullification of this draft put the state of emergency specified in many laws and regulations (including the Constitution of the People's Republic of China and Security Administration Punishment Law) in an awkward situation. It caused disorderliness of legal terms and even legal systems. Also, there are provisions regarding nationwide and local mobilization. As a consequence, "emergency responses" and "emergency administration" appear to be more disorderly. Under the background of comprehensively deepening reforms, a consensus has been reached to legally regulate government power. This is reflected from the list of government powers released by the central government and construction of service-oriented government. Therefore, from the structure of legislation systems, only if the Emergency Law is formulated to clarify that the state of emergency is an abnormal state opposite to the normal state for the purpose of legally regulating many administrative measures adopted by the governments for epidemic prevention and control can it become possible to construct complete emergency management systems, mobilization systems, and more scientific legal systems for the construction of law-based government. The emergency system is a prevalent practice in most modern countries. By formulating the Emergency Law, an emergency can be identified as abnormal state opposite to the normal state to legally regulate numerous administrative measures taken by the governments for epidemic prevention and control, in order that epidemic can be better prevented and controlled with administrative measures beyond normal legal authorities. In particular, the state of emergency has been specified in the Chinese Constitution and pertinent law, whereas no emergency law is available for regulating emergencies. As a result, factual legal concepts and language logics are disorderly; systems are incomplete. To prevent and control COVID-19, cities, residential quarters, and village communities were blocked in China on a large-scale basis. Besides, people's travel, gathering, association, and traffic were restricted and controlled. Materials were distributed and produced all over China. Medical personnel were urgently transferred on a nationwide basis. Lots of enterprises suspended production, and many suspected cases were isolated for observation.

In fact, China entered a state of emergency at that time. Some people think that once the first-level significant public health emergency response is activated in provinces and cities, it means that the country has entered the state of emergency. Hence, it is unnecessary to additionally legislate a separate law. In fact, from the perspective of law, the two circumstances are completely different. Major public health emergency response is activated based on the National Public Health Emergency Response Plan, which is drafted on the basis of the Law of the People's Republic of China on the Prevention and Treatment of Infectious Diseases. However, this law is mainly about the major measures for preventing and controlling infectious diseases. Instead, it does not grant the governments related to administrative rights. Once a country claims the state of emergency, normally, civil rights protected by some law will be restricted, and the governments' related rights will be expanded for epidemic prevention 
and control. Meanwhile, government power can be restricted to prevent governments from abusing their power due to inappropriate power expansion, in order to protect some of the citizens' fundamental rights and strengthen the governments' ruling by law under the state of emergency.

Therefore, from the perspective of legislation, efforts shall be speeded up to formulate an emergency law to clearly define legal connotation and extension of this law, in order that administrative organs can correctly distinguish emergencies from states of emergency. Clarify legal procedures and scope of power exercised by administrative organs, what emergency measures can be adopted, holders of rights, legal responsibilities, supervision, and relief under the state of emergency. The first section shall be general provisions. It shall mainly introduce the concept and basic principle of the state of emergency. The second section shall be about monitoring and early warning. It primarily specifies government authorities in charge of monitoring and early warning under the state of emergency and normal circumstances as well as connections of specific jobs, rights, and legal responsibilities. Section 3 describes authorities under the state of emergency, especially the effectiveness of other law under the state of emergency, and restrictions of citizens' fundamental rights. The fourth section shall be about legal responsibilities, while the fifth section shall introduce power supervision and relief under the state of emergency. Section 6 shall be about supplementary provisions. Secondly, revise outdated clauses of existing emergency law and regulations, including the Emergency Response Law of the People's Republic of China, Law of the People's Republic of China on the Prevention and Treatment of Infectious Diseases and Regulations on Public Health Emergency. Unify legal terms, anti-epidemic standards, and legal authorities: update virus classification and coordinate other law with the emergency law. Thirdly, appropriately cope with the relationships between event-based legislation and phased legislation; strengthen the formulation of comprehensive law and regulations. In particular, emergency-related law shall be linked with normal law, including the Administrative Compulsory Law, Administrative Procedural Law, Regulations on the Disclosure of Government Information, Administrative Expropriation Law, and Law on State Compensation. Add clauses of the emergency law to normal law, and appropriately handle the relationships between emergency-related law and emergency response plans, in order that legal systems can be more systematic, complete and coordinated.

\section{Construction of an Emergency Support Mechanism for Citizens' Fundamental Rights}

First of all, construct an emergency support mechanism for citizens' fundamental rights. Add content on the authorities for restricting citizens' fundamental rights, relief approaches, and relief mechanisms under the state of emergency to Section 3 of the aforementioned emergency law. Secondly, revise related legal provisions of the existing legal emergency system. Classify states of emergency and corresponding legal authorities. Thirdly, build special governmental and judicial authorities for protecting rights under emergencies. Guarantee diversity and smoothness of relief approaches with new mobile and network communication technologies online and offline.

Epidemic prevention and control, which is for safeguarding public health security, involves public interests, whereas private interests are concerned in protecting citizens' fundamental rights. According to the modern spirit and principle of the rule of law, when epidemic prevention and control conflict with private interests, public interests shall be more important than private interests, and thus the latter will be restricted and even reduced. 
However, individuals' fundamental rights shall not be infinitely reduced. There shall be an appropriate boundary and balance between both of them, which is in line with the spirit of ruling by law. In particular, relief approaches available for protecting citizens' fundamental rights under existing law might be impacted by the epidemic during prevention and control, thus failing to play their roles. For instance, how shall administrative counterparts harmed by administrative measures for epidemic prevention and control application for administrative reviews or file administrative lawsuits against the administrative behaviors infringing upon their rights and interests during epidemic prevention and control? Notably, in affected areas, roads and neighborhoods were blocked, while citizens' freedom and movement were restricted. Impacted by COVID-19, administrative review organizations and courts couldn't carry out work. Under this circumstance, how to protect fundamental legitimate rights and interests of citizens by law, especially when many citizens' fundamental rights were infringed upon during epidemic prevention and control, as mentioned above? All these are fairly important legal issues. President Xi Jinping has mentioned several times that internet plus governance is an important reform orientation for the construction of law-based government. In consideration of above special circumstances of epidemic prevention and control under which citizens' don't enjoy fundamental rights, while such rights are protected by law, including the Constitution of the People's Republic of China and Law of the People's Republic of China on the Prevention and Treatment of Infectious Diseases, online platforms for rapid administrative reviews and courts' online lawsuit acceptance are recommended to be built to realize internet plus governance. Compared with traditional offline methods for protecting citizens' fundamental rights, an online emergency mechanism for protection of such rights is more convenient, rapid, efficient, and more adaptable to special epidemic circumstances. Furthermore, this mechanism is favorable for constructing a unified joint defense, control, and command mechanism for governments at varying levels. This not only facilitates governments' administration by law at varying levels under the epidemic situation, but also increases judicial efficiency and reduces harms of illegitimate power expansion to citizens' fundamental rights, thus making it helpful for the construction of law-based government.

\section{Constructing a Coordinated Public Health Emergency Response Mechanism for} Governments at Varying Levels

A coordinated public health emergency response mechanism is needed for governments at different levels. The key is to prevent governments from separating administrative bodies in a state of emergency, and to avoid conflicts in case of emergency. It is inappropriate to bring overall optimal effects into play with the minimum legal costs. For instance, COVID-19 wasn't promptly reported to the central government owing to the mechanism for reporting to higher authorities level by level as specified by the Law of the People's Republic of China on the Prevention and Treatment of Infectious Diseases. Hence, the following suggestions are given: Firstly, in legislating the aforementioned emergency law, the emergency commands under the state of emergency shall be further coordinated, integrated, and clarified. Besides, revise and sort out outdated legal articles to make them adaptable to social development. Secondly, establish special organizations and a complete emergency coordination mechanism. Rights, responsibilities, and legal status of the Emergency Management Office, the State Council, are suggested to be expanded. Establish corresponding affiliates to local governments at varying levels, making them become special standing emergency command organizations. Thirdly, make emergency management flat with advanced technologies such as the internet, mobile 
communications, and cloud data. Break limits of time and space-dependent upon strengths of new technologies to make emergency information public and connected, in order that local governments can directly report to the central government. In this manner, the emergency management of governments at varying levels can be coordinated.

Since the outbreak of COVID-19, governments at varying levels promulgated policies for epidemic prevention and control in succession. Till now, the domestic epidemic has been effectively controlled. Of course, some legal issues have emerged in the process of COVID-19 prevention and control. The issues on legal policy supervision and coordination of governments at varying levels are especially prominent. Although joint prevention and control mechanisms were established for governments at varying levels from central to local governments, policies were still not coordinated, and there was a lack of legal supervision. The administrative measures released by some local governments for COVID-19 prevention and control were not in line with the law. For instance, some local governments arbitrarily blocked roads and cut off traffic without obtaining legal authorization or going through statutory procedures. This should be ascribed to the incompleteness of pertinent laws and regulations as well as some local governments' lack of legal ideas. In particular, no emergency law is available in China. In the face of the massive, contagious, and severe COVID-19, the governments at varying levels took administrative measures based on different laws and regulations, which appeared to be scattered, disorderly and unsystematic. Notably, some of the laws and regulations were promulgated more than ten years ago, and never revised over the years. Thus, they no longer suit the actual situation of epidemic prevention and control, changing national conditions of China and fast-growing society as well as tremendous changes to traffic networks and regional population flow, and so on. They are even no longer adaptable to the strong destructive power of viruses arising from virus mutations and variations such as periodical, contagious, and drugresistant viruses infections.

On the contrary, related foreign law has been revised frequently. For example, regulations on disaster prevention dominated by the Federal Emergency Management Agency of the United States have been revised for more than 100 times over the past 100 years. Over 20 years from its enactment in 1999 to 2019, Russian Federal Law on Public Health and Epidemic Prevention has been revised for 41 times, and twice per year on average. If the revision of law and regulations does not keep up with social development, the law and regulations will become outdated.

Above all, it is necessary to constantly improve the construction of the legal system on public health emergencies, subdivide related law and regulations, approve the emergency law as early as possible, clarify rights and responsibilities of legal anti-epidemic subjects, particular law and regulations, so as to promote the construction of law-based government.

\section{Conclusions}

This paper focuses on preliminary research on legal issues related to epidemic prevention, control, and construction of law-based government. It roughly analyzes legal issues regarding legislation, government law enforcement, supervision, and relief in law and regulations pertinent to epidemic prevention and control. Besides, an attempt is made to put forward countermeasures for improving the law. Legal systems, law, and provisions on Chinese major public health emergencies aren't specific, detailed, or complete. As a consequence, some legal issues have emerged in the context of counteraction to COVID-19. Based on former 
research, this paper summarizes and sorts out the content and legal issues concerning epidemic prevention and construction of law-based government. Besides, legal cases regarding the construction of law-based government in the context of counteraction to COVID-19 have been collected, analyzed, and studied with related legal knowledge.

\section{[D] References}

Aristotle (2013) Politics. The Commercial Press.

Bazaluk, Oleg, and Svitlana Balinchenko. The Ethics Laws as a Basis for Building a Cosmic Civilization. The Sofia Republic. Philosophy and Cosmology, Volume 24, 2020: 131139. https://doi.org/10.29202/phil-cosm/24/13

Huang, Xuexian (2015) The Intrinsic Characteristics of the Government under the Rule of Law and Its Realization. Jiangsu Social Sciences, 2015, (01): 1-8.

Research Center for Government by Law, China University of Political Science and Law (2014). Government Report on Ruling by Law in China. China Renmin University Press, 2014. 97-143.

Rousseau (2004) The Social Contract. Translated by He Zhaowu. Beijing: Commercial Press, $7-63$.

Zhang, Hengshan (2008) Essentials of Western Legal Masterpieces. People's Publishing House, 2008, 43-72. 